\title{
Natural Radionuclides Concentrations and Annual Effective Dose in Seasonal Fruits of Bangladesh
}

\author{
Rumman Mustakim ${ }^{1}$, Jannatul Ferdous ${ }^{2, ~}$, Aleya Begum ${ }^{2}$, Aminul Islam ${ }^{1}$ \\ ${ }^{1}$ Department of Physics, University of Rajshahi, Rajshahi, Bangladesh \\ ${ }^{2}$ Health Physics Division, Atomic Energy Center, Dhaka, Bangladesh
}

Email address:

ferdous28@yahoo.com (J. Ferdous)

${ }^{*}$ Corresponding author

\section{To cite this article:}

Rumman Mustakim, Jannatul Ferdous, Aleya Begum, Aminul Islam. Natural Radionuclides Concentrations and Annual Effective Dose in Seasonal Fruits of Bangladesh. Nuclear Science. Vol. 3, No. 3, 2018, pp. 28-35. doi: 10.11648/j.ns.20180303.11

Received: October 1, 2018; Accepted: October 17, 2018; Published: November 9, 2018

\begin{abstract}
The aim of the present study was to investigate the activity concentrations of natural radionuclides in different seasonal fruits of Bangladesh. In total 20 samples of 16 different kinds of fruits were collected from the local markets of Bangladesh. The radioactivity of these samples was measured by using Gamma Spectrometry System. The radioactivity of natural radionuclides in the studied seasonal fruit samples were found to be ranged from BDL to $31.13 \pm 10.63 \mathrm{Bqkg}^{-1}$ with an average $10.95 \mathrm{Bqkg}^{-1}$ due to ${ }^{238} \mathrm{U}$, from $1.55 \pm 0.73$ to $34.59 \pm 7.43 \mathrm{Bqkg}^{-1}$ with an average $6.68 \mathrm{Bqkg}^{-1}$ due to ${ }^{232} \mathrm{Th}^{2}$ and from BDL to $733.25 \pm 61.17 \mathrm{Bqkg}^{-1}$ with an average $308 \mathrm{Bqkg}^{-1}$ due to ${ }^{40} \mathrm{~K}$. Artificial radionuclide was not found in the studied fruit samples. The maximum activities of ${ }^{238} \mathrm{U},{ }^{232} \mathrm{Th}$ and ${ }^{40} \mathrm{~K}$ were observed, respectively in coconut, jujube and papaya. However, the average concentrations of all radionuclides mentioned above in the studied samples were found to be less than the world average. The total annual internal effective dose from the consumption of radioactive fruits was found to be $8.39 \mu \mathrm{Sv} / \mathrm{y}$. The value the annual effective dose in all samples in this study was lower than ICRP 72 ; therefore, the values natural radioactivity and annual effective dose in the seasonal fruits are found to be safe and no health-hazards are createdfor the population of Bangladesh.
\end{abstract}

Keywords: Radioactivity, Seasonal Fruit, Gamma Spectrometry System, Annual Effective Dose

\section{Introduction}

Natural radioactive decay series such as ${ }^{238} \mathrm{U}$ and ${ }^{232} \mathrm{Th}$ as well as singly occurring radionuclides such as ${ }^{40} \mathrm{~K}$ exist in the earth and atmosphere in varied levels. The radioactivity present on air or in the agricultural land and in soil may transfer to the crops grown on it. It happens; however, that an amount of some radioactive elements find their way into human bodies[1]. Generally, the plants may cause accumulation of radionuclides in their organs, which may additional rely on the chemical and physical properties of the soil. So, there may be multiplied risk to human population via food chain. The main sources of components from the environment to plants are: air, water and also the soil [2]. Humans are exposed to both internal and external radiation from these natural sources. Internal exposure occurs through the intake of terrestrial radionuclides through inhalation or ingestion. Inhalation exposure dose results from the existence of dust particles in air, including radionuclides from ${ }^{238} \mathrm{U}$ and ${ }^{232} \mathrm{Th}$ decay series. The biggest contribution toinhalation exposure comes from short half-life decay products of radon. Ingestion exposure dose mostly results from ${ }^{238} \mathrm{U}$ and ${ }^{232} \mathrm{Th}$ series radionuclides and ${ }^{40} \mathrm{~K}$ in drinking water and foodstuff. In addition, ${ }^{137} \mathrm{Cs}$ is the most important fission product released to the environment as a result of nuclear activities, because this radionuclide rapidly passes to foodstuffs and creates a dose effect [3]. In some parts of the world, population growth and movement, industrial development and food security have resulted in pressure to use agricultural lands containing relatively high levels of radioactivity, for instance in the monazite areas of India and Brazil, and in parts of Iran with ${ }^{226} \mathrm{Ra}$ anomalies where exposures up to tens of $\mathrm{mSv}$, and in extreme cases $100 \mathrm{mSv}$, occur annually [3, 4]. Bangladesh is located at $88^{\circ} 01^{\prime \prime} \mathrm{E}-92^{\circ} 41^{\prime \prime} \mathrm{E}$ longitude and latitude $20^{\circ} 34^{\prime \prime} \mathrm{N}-26^{\circ} 38^{\prime \prime} \mathrm{N}$ which is geographically downward to India. So, it is highly possible that Bangladesh is suffering from radioactivity due to situation of the source 
of the rivers in India. There are also some rivers which are situated in Nepal, Bhutan and flown through India. Therefore its land might be contaminated by radioactive sources from upstream. Bangladesh enjoys generally a sub-tropical monsoon climate. So, Bangladesh is one of the notable growers of a vast range of fruits. More than 60 varieties of fruits are being grown in the country. Among them, mango, orange, pineapple, banana, Litchi, coconut, lemons, pummel, guavas etc. are the main fruits of Bangladesh. Fruits are of different colors, sizes and taste. Some are solid while some are juicy. The fruits that we eat contribute to some extent to our internal exposure to radiation because these fruits are naturally radioactive. The radionuclides present in the environment transfer to fruits through (i) uptake from soil through roots and (ii) direct absorption through aerial parts of the plants. These radionuclides, when accumulated over the period of time in foods and water, constitute a direct route of natural exposure to human population when they are consumed. Due to possible transfer of these radionuclides and their progeny from fruits to human body, it is necessary to assess potential radiation doses. The present study aimed to determine the radionuclide concentrations in seasonal fruits of Bangladesh.

\section{Materials and Method}

\subsection{SampleCollection and Preparation}

Twenty samples of seasonal fruits were collected from the local market of Rajshahi and Natore district, Bangladesh during the month of May, 2015 to April, 2016. Each of the samples weighed approximately $2 \sim 10 \mathrm{~kg}$. The fruits were peeled (if necessary) and eatable parts were separated by cutting into pieces about $2 \mathrm{~cm}$ in length and $0.5 \mathrm{~cm}$ in depth. The samples were sun dried ( 7 to 10 days) by spreading them on separate sheets of dry paper. After that, the samples were packed in dry polyethylene bags. The bags were then labeled with sample codes and sealed. In the laboratory, the collected samples were dried in an electric oven approximately $24 \mathrm{hrs}$ at $110^{\circ} \mathrm{C}$. The dried samples were grinded by crowbar, sieved and then reweighted. The measured weight of the sample gave the dry weight. The dry weight of the sample was varied from $135 \mathrm{gm}$ to $248 \mathrm{gm}$. Finally each of the samples was transferred to cylindrical plastic-container. The containers were approximately of equal size and shape (i.e. diameter 6.5 $\mathrm{cm}$ and height $7.5 \mathrm{~cm}$ ). The containers were then labeled properly and sealed tightly, wrapped with thick vinyl tapes around their screw necks. The samples were stored in order to allow the in-growth of uranium and thorium decay products and achievement of equilibrium for ${ }^{238} \mathrm{U}$ and ${ }^{232} \mathrm{Th}$ with their respective progeny to get ready for measurements.

\subsection{Gamma Spectrometry Instrumentation}

In this study, the radioactivity concentration of radionuclides in fruit samples was measured byusing a highresolution gamma-ray spectrometry system in a low background configuration. The High Purity Germanium
Detector was p-type coaxial detector coupled with a Mestro32 Multichannel Analyzer (MCA) and associate microprocessors. The effective volume of the detector was $83.47 \mathrm{~cm}^{3}$. It was cooled with a liquid nitrogen cryostat to reduce the leakage current. The relative efficiency of the detector was $19.6 \%$ with resolution of $2.3 \mathrm{keV}$ at $1.332 \mathrm{MeV}$. The detector was enclosed with a cylindrical lead shield to reduce the background radiation from various natural radiation sources and to isolate from other radiation sources used in nearby surroundings. The lead shielding was graded with an inner layer of copper to reduce the contribution from $\mathrm{Pb}$ X-ray fluorescence and the top was covered by round movable steel and a lead pate. The high voltage bias was applied to the detector through the pre-amplifier from a high voltage supplier (HV supply model ORTEC459). A high voltage bias of +3200 volts was applied for the present measurements in order to operate the HPGe detector. Figure 1 shows the block Diagram of HPGe detector system.

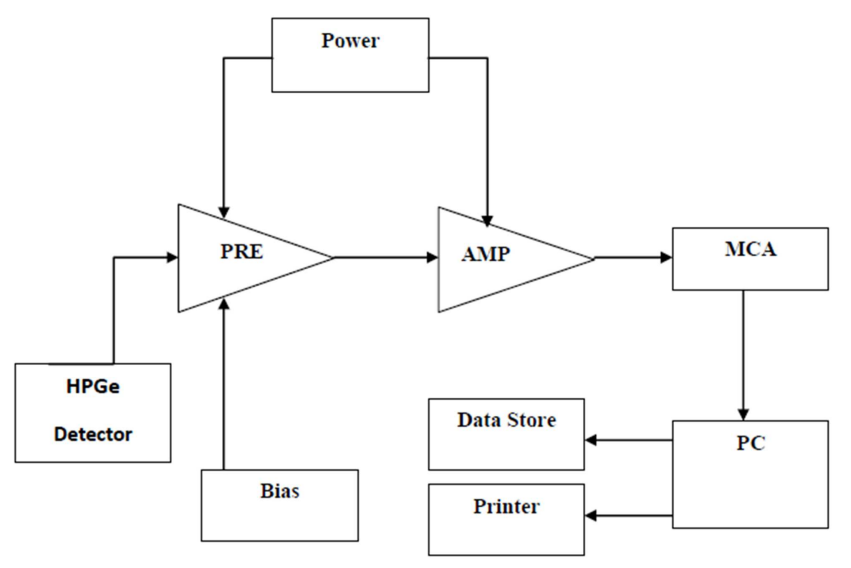

Figure 1. Block diagram of HPGe detector system.

The energy calibration of the MCA was obtained using standard point sources such as ${ }^{22} \mathrm{Na},{ }^{57} \mathrm{Co},{ }^{60} \mathrm{Co},{ }^{133} \mathrm{Ba},{ }^{137} \mathrm{Cs}$, etc. The efficiency of the detector for different radionuclides of interest of different energies were determined by mixing standard sources of known activities and different energies such as 122, 245, 344, 411, 444, 779, 963, 1086, 1112 and $1408 \mathrm{keV}$ supplied by Health Physics Division, Atomic Energy Centre, Dhaka and following the standard method. The efficiency calibration curve thus obtained was employed in the different energy peaks covering the range up 60 to $2000 \mathrm{keV}$ to obtain the efficiency of the detector for the particular gamma ray energy of interest. The geometry of the counting samples was the same as that of the standard samples. In order to determine the background distribution in the environment around the detector, an empty sealed beaker was counted in the same manner and in the same geometry as the samples. The background spectra were used to correct the net peak area of gamma rays of measured isotopes. Figure 2 shows the efficiency calibration curve. 


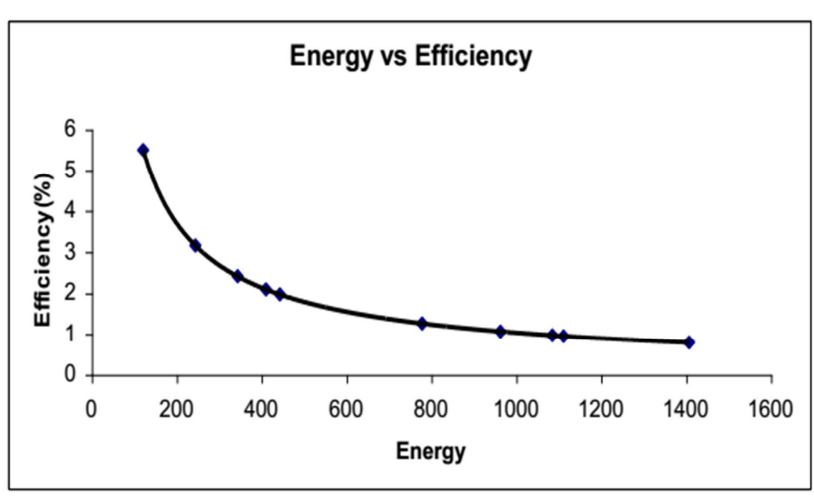

Figure 2. Efficiency calibration Curve.

\subsection{Measurement of Radioactivity}

To qualitatively identify the contents of radionuclides in northern regions food grain and vegetable samples and to quantitatively determine their activities, all prepared samples were measured by means of gamma-ray spectrometry system using ORTEC high purity Ge-detector for $15000 \mathrm{sec}$. The equal counting time for background and sample measurement was chosen to minimize the uncertainty in the net counts. The spectrum of each sample was analyzed and the identification of unknown radionuclide was carried out by considering their peak centroid energies. The centroid energies of the peaks from the spectrum were compared with the reference gamma-ray energies obtained from the literature. The radionuclides contained in the samples were identified and the areas under the peaks were used to determine the activity concentrations of each nuclide. The activity concentrations of ${ }^{238} \mathrm{U}$ and ${ }^{232} \mathrm{Th}$ were determined from the average concentration of nuclides $\left[{ }^{214} \mathrm{~Pb}\right.$
$(295.2 \mathrm{keV}),{ }^{214} \mathrm{~Pb}(351.9 \mathrm{keV}),{ }^{214} \mathrm{Bi}(609.3 \mathrm{keV})$ and ${ }^{214} \mathrm{Bi}$ $(1120.2 \mathrm{keV})]$ and $\left[{ }^{212} \mathrm{~Pb}(238.6 \mathrm{keV}),{ }^{208} \mathrm{Tl} \quad(583.1 \mathrm{keV})\right.$, and $\left.{ }^{228} \mathrm{Ac}(911.2 \mathrm{keV}),{ }^{228} \mathrm{Ac}(968.9 \mathrm{keV})\right]$ respectively. The activity concentrations of ${ }^{40} \mathrm{~K}$ were determined directly by measurement of the gamma ray transitions at $1460.8 \mathrm{keV}$. The specific activity, in terms of the activity concentration, is defined as the activity per unit mass of the sample. The specific activity of individual radionuclides in food grain and vegetable samples is given by the following equation:

$$
A=\frac{N \times 100 \times 1000}{\mathrm{P} \gamma \times \mathcal{E} \times W}
$$

Where, $\mathrm{N}$ is Net counts per second (cps), $\mathrm{P}_{\gamma}$ is Transition probability of gamma ray or Branching, $\varepsilon$ is Efficiency in percent and Wis Weight of the sample in gm. The term net count rate associated with the activity measurement is the difference between the gross count rate of the sample and the background count rate. Each count rate includes standard deviationand the standard deviation of the net count rate can be expressed as,

$$
\sigma= \pm \sqrt{A_{s} / T_{s}+A_{b} / T_{s}}
$$

Where, $A_{s}$ is Sample count rate and $A_{b}$ is Background count rate in cps, $T_{s}$ is Sample count time and $T_{b}$ is background count time. The standard deviation is also a measure of the dispersion of a collection of numbers. It can apply to a probability distribution, a random variable, a population or a data set. The standard deviation is usually denoted with the letter $\sigma$. Figure 3 shows a typical gamma spectrometry system for fruit sample.

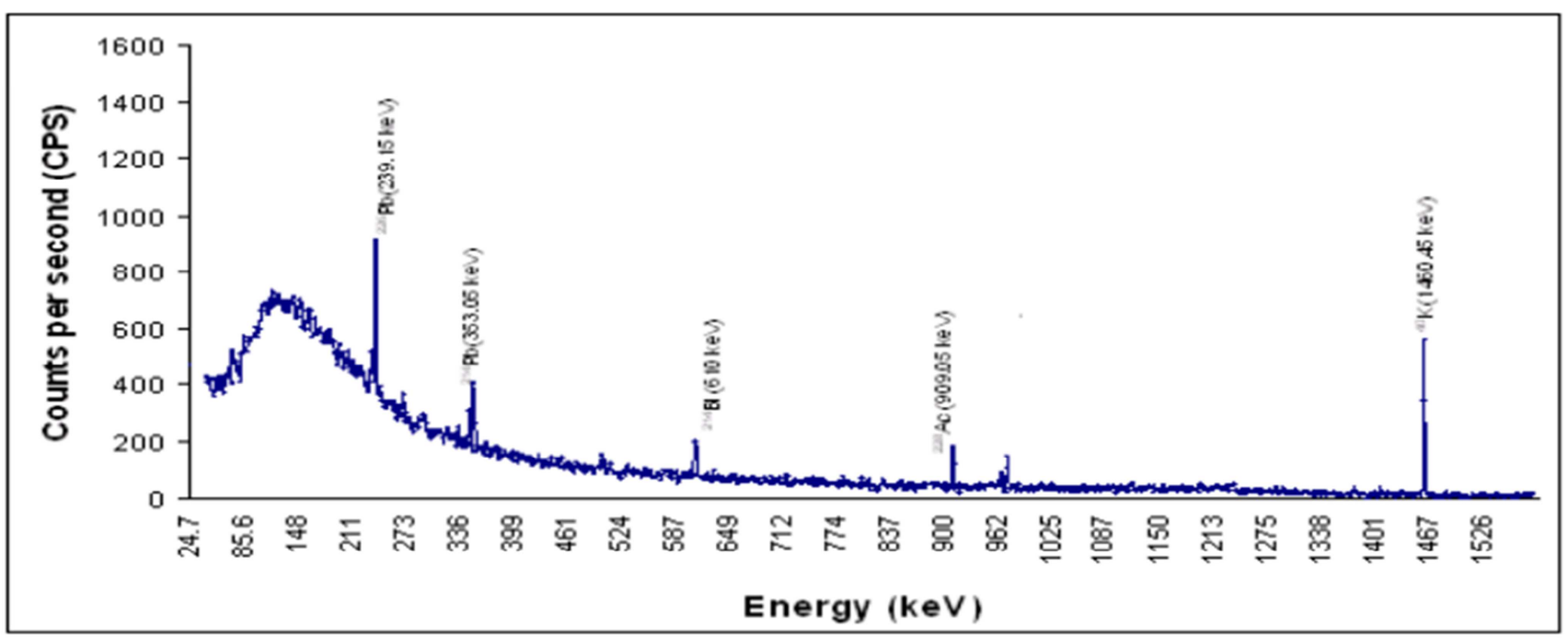

Figure 3. A typical gamma spectrometry system for fruit sample.

\subsection{Analysis of Effective Dose}

During this study, it was also calculated the annual effective dose. As a result of the intake of foods was performed supported the metabolic model developed by
ICRP 72 [5] which it's can be determined using the following equation:

$$
D_{r f}\left(S v y^{-1}\right)=\sum\left(C_{r} A_{r f}\right) * R_{f}
$$


Where, $\mathrm{D}_{\mathrm{rf}}$ is the annual effective dose; $\mathrm{C}_{\mathrm{r}}$ is the effective dose conversion factor of the nuclide $(\mathrm{r}) ; \mathrm{A}_{\mathrm{rf}}$ is the specific activity of the nuclide (r) in the ingested food ( $\mathrm{f}, \mathrm{Bqkg}^{-1}$, fresh weight) andR $R_{f}$ is the consumption rate of the food item (f, $\mathrm{kgy}^{-1}$ ).

\section{Results and Discussion}

\subsection{ActivityConcentration in Seasonal Fruits}

The activity concentrations of ${ }^{238} \mathrm{U},{ }^{232} \mathrm{Th}$ and ${ }^{40} \mathrm{~K}$ in the collected fruit samples have been measured and are given in Table 1.

Table 1. Activity concentrations of ${ }^{238} U^{232}$ Thand ${ }^{40}$ Kin the fruit sample.

\begin{tabular}{lllll}
\hline \multirow{2}{*}{ Sample No. } & Sample Name & \multicolumn{2}{l}{ Activity Concentration in Bqkg-1 } & \\
\cline { 3 - 5 } & & ${ }^{238} \mathbf{U}$ & $2.78 \pm 0.67$ & \\
\hline 1 & Mango-1(Fazliaam) & $7.39 \pm 1.37$ & $7.92 \pm 7.10$ & $123.66 \pm 43.75$ \\
2 & Mango-2(Atiaam) & $1.95 \pm 1.33$ & $3.89 \pm 0.77$ & $182.84 \pm 85.95$ \\
3 & Jackfruit(Kathal) & $23.29 \pm 8.15$ & $1.63 \pm 1.05$ & $220.27 \pm 49.40$ \\
4 & Litchi (Lichu) & $13.32 \pm 12.22$ & $5.28 \pm 0.87$ & BDL \\
5 & Pineapple (Anaros) & BDL & $3.82 \pm 0.75$ & $247.18 \pm 53.39$ \\
6 & Banana-1 (Sobri kola) & $2.47 \pm 1.67$ & $1.55 \pm 0.73$ & $287.16 \pm 48.64$ \\
7 & Banana-2 (Sagor kola) & $4.09 \pm 2.77$ & $5.43 \pm 0.86$ & $443.92 \pm 56.63$ \\
8 & Banana-3 (Champa kola) & $24.63 \pm 8.62$ & $4.55 \pm 0.97$ & $322.81 \pm 53.40$ \\
9 & Banana-4(Bichi kola) & $1.53 \pm 1.07$ & $10.67 \pm 5.09$ & $362.46 \pm 64.51$ \\
10 & Guava (Peyara) & $24.48 \pm 7.85$ & $11.33 \pm 3.25$ & $347.93 \pm 80.71$ \\
11 & Ber (Boroi) & $1.89 \pm 1.39$ & $34.59 \pm 7.43$ & $232.79 \pm 51.09$ \\
12 & Jujube(Kool) & $5.59 \pm 2.25$ & $2.90 \pm 0.80$ & $236.17 \pm 79.24$ \\
13 & Papaya (Pepe) & BDL & $6.68 \pm 1.08$ & $733.25 \pm 61.17$ \\
14 & Star Fruit (Kamranga) & $6.55 \pm 9.82$ & $2.36 \pm 0.65$ & $596.78 \pm 69.62$ \\
15 & Cherimoya (Meowa) & $4.33 \pm 2.06$ & $5.16 \pm 0.75$ & $313.96 \pm 46.39$ \\
16 & Wood Apple (Bel) & $6.57 \pm 4.38$ & $2.78 \pm 0.69$ & $300.74 \pm 45.37$ \\
17 & Sapodilla (Sofeda) & $7.71 \pm 7.07$ & $5.45 \pm 1.01$ & $215.63 \pm 46.57$ \\
18 & Coconut(Narkel) & $31.13 \pm 10.63$ & $7.12 \pm 1.52$ & $36.84 \pm 60.89$ \\
19 & Bangi & $21.74 \pm 15.34$ & $7.85 \pm 1.33$ & $307.96 \pm 97.49$ \\
20 & Water Melon (Tormuj) & $8.44 \pm 2.36$ & & $665.66 \pm 85.91$ \\
\hline
\end{tabular}

$\mathrm{BDL}=$ Below Detection Limit

Table 2. Ranges of activity concentration and average activity concentration of ${ }^{238} U,{ }^{232} T h$ and ${ }^{40} \mathrm{~K}$ in the collected twenty fruit samples.

\begin{tabular}{lll}
\hline Radionuclides & Ranges of activity concentration $\left(\mathbf{B q k g}^{-\mathbf{1}}\right)$ & Average activity concentration $\left(\mathbf{B q k g}^{-\mathbf{1}}\right)$ \\
\hline${ }^{238} \mathrm{U}$ & $\mathrm{BDL}-31.13$ & 10.95 \\
${ }^{232} \mathrm{Th}$ & $1.55-34.59$ & 6.68 \\
${ }^{40} \mathrm{~K}$ & $\mathrm{BDL}-733.25$ & 308.90 \\
\hline
\end{tabular}

The ranges of activity concentration and average activity concentration of different radionuclides in the collected fruit samples are shown in table-2. The activity concentrations due to ${ }^{238} \mathrm{U}$ vary from $\mathrm{BDL}$ to $31.13 \pm 10.63 \mathrm{Bqkg}^{-1}$ with average $10.95 \mathrm{Bqkg}^{-1}$, from $1.55 \pm 0.73$ to $34.59 \pm 7.43 \mathrm{Bqkg}^{-1}$ with average $6.68 \mathrm{Bqkg}^{-1}$ due to ${ }^{232} \mathrm{Th}$ and from $\mathrm{BDL}$ to 733.25 $\pm 61.17 \mathrm{Bqkg}^{-1}$ with average $308.90 \mathrm{Bqkg}^{-1}$ due to ${ }^{40} \mathrm{~K}$. Among all the natural radioisotopes in the present study, the activity concentration of ${ }^{40} \mathrm{~K}$ is highest. This may be due to the high concentration of ${ }^{40} \mathrm{~K}$ and higher transfer factor of the radionuclide because of the specific metabolic processes involving potassium in plants [6]. Also, the extra use of Murate of Potass fertilizer may be another factor causing the increase of ${ }^{40} \mathrm{~K}$ concentration in the fruit samples. The maximum activity of ${ }^{40} \mathrm{~K}$ is found in papaya and minimum in litchi. The highest activities of ${ }^{238} \mathrm{U}$ and ${ }^{232} \mathrm{Th}$ are found in the samples coconut and jujube respectively. The minimum activity of ${ }^{238} \mathrm{U}$ is found in pineapple and papaya, the minimum activity of ${ }^{232} \mathrm{Th}$ is found in banana-2 (Sagor). Banana is one of the most important foods which stood first position among the fruits producing in Bangladesh and supplies $42 \%$ of the total fruit requirements in the country [7]. Again an informal expression of ionizing radiation exposure called banana equivalent dose (BED) is intended as a general educational example to indicate the potential dose due to naturally occurring radioactive isotopes by eating one average-sized banana. Among different variety, on the basis of their local name the most popular and demandable four varieties of bananas are studied in this present work. Banana contains naturally occurring radioactive material mainly in the form of Potassium-40. The bar diagram comparing the activity concentrations of ${ }^{40} \mathrm{~K}$ for banana samples are shown in Figure 4. From Figure 4, It is observed that the maximum activity of ${ }^{40} \mathrm{~K}$ is found in banana-2 (Sagor) and minimum in banana-1 (Sobri). Figure 5 represents the bar diagram which shows the activity concentrations of ${ }^{238} \mathrm{U}$ and ${ }^{232} \mathrm{Th}$ in banana samples. It is observed that both the activity concentrations of ${ }^{238} \mathrm{U}$ and ${ }^{232} \mathrm{Th}$ are highest in banana-3 (Champa kola). The average activity concentrations of ${ }^{238} \mathrm{U}$, ${ }^{232} \mathrm{Th}$ and ${ }^{40} \mathrm{~K}$ in banana samples are found $8.18,3.84$ and $354.08 \mathrm{Bqkg}^{-1}$ respectively. 


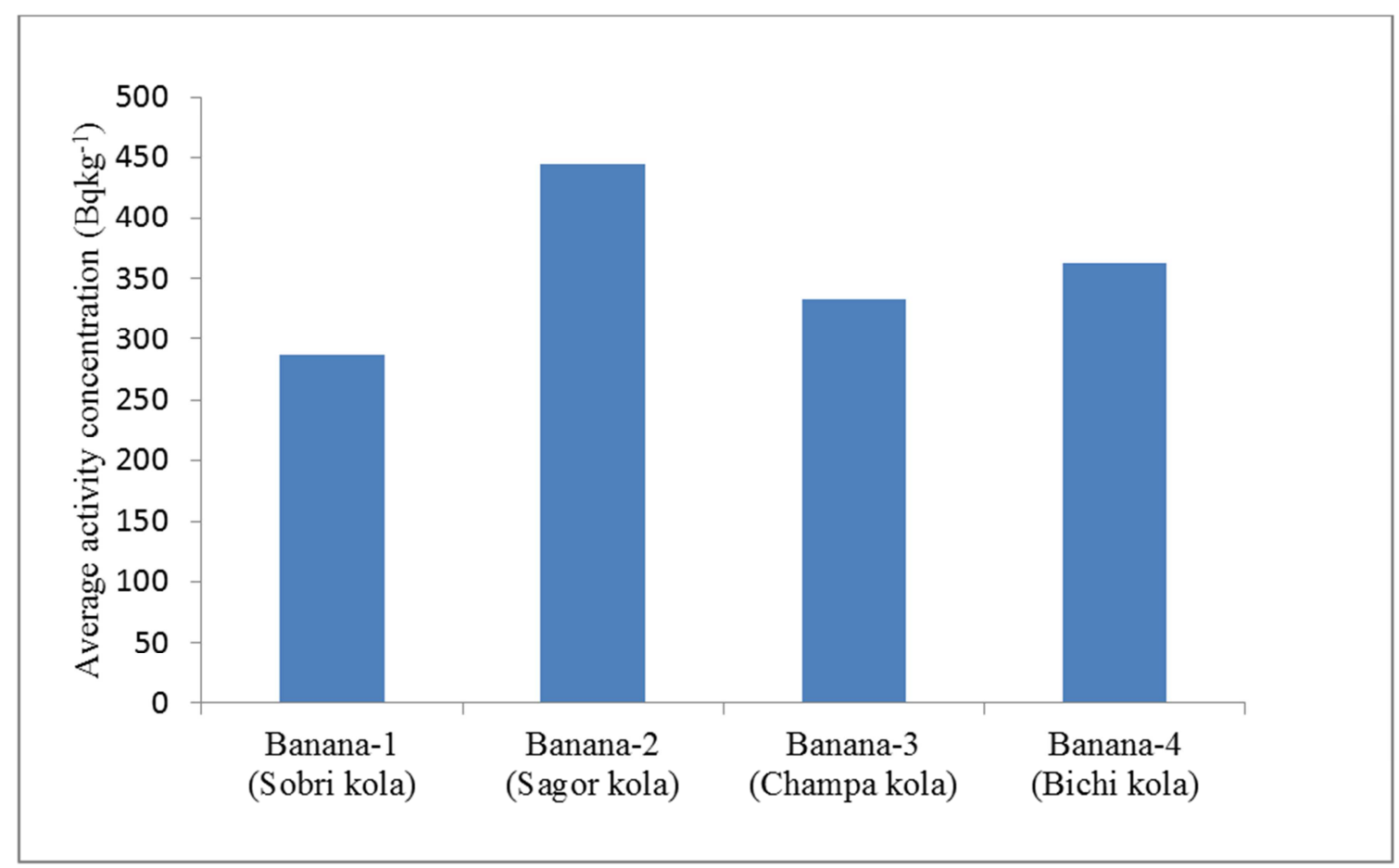

Figure 4. Comparison of the activity concentration of ${ }^{40} \mathrm{~K}$ for variety of banana samples.

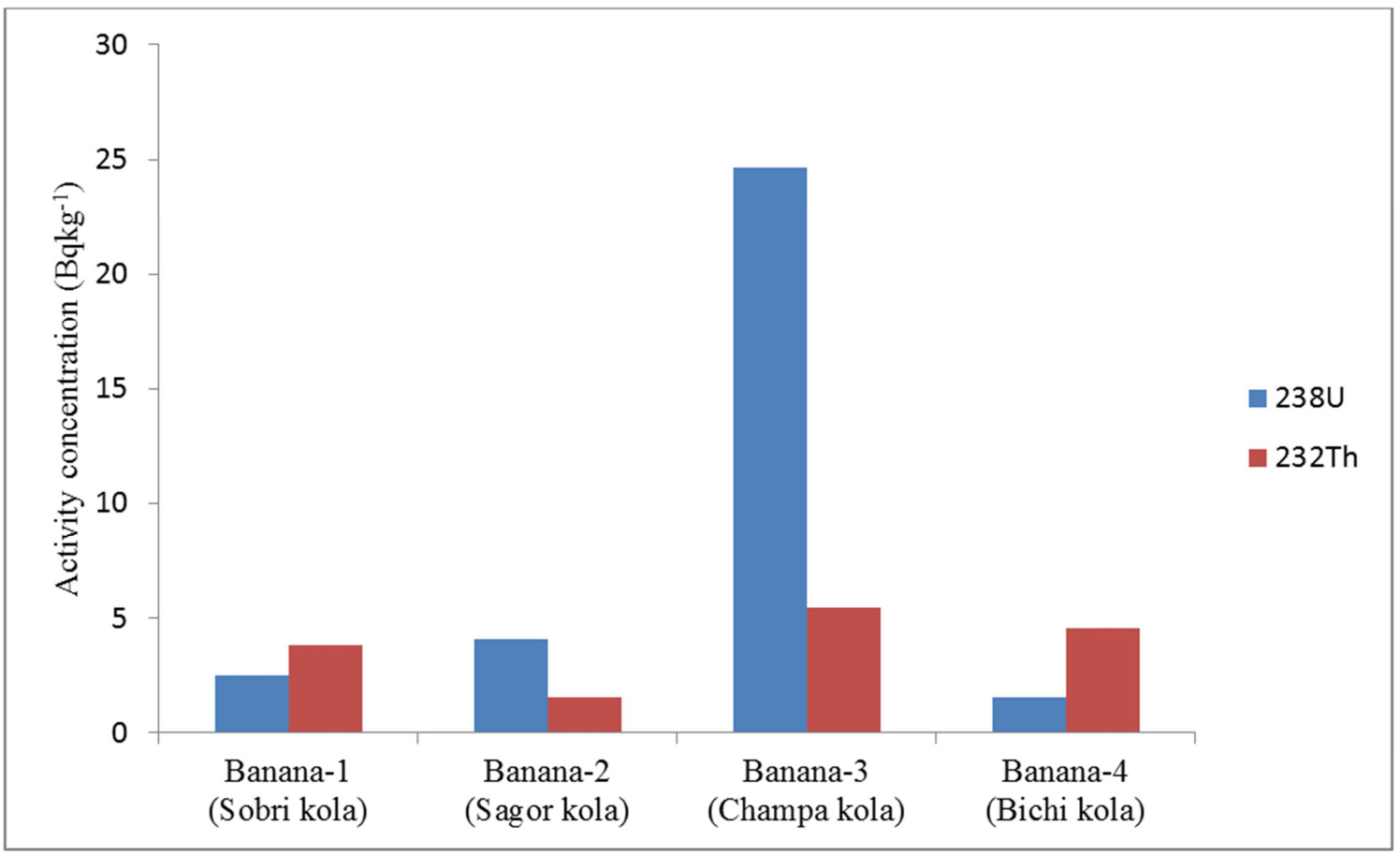

Figure 5. Comparison of the activity concentrations of ${ }^{238} U$ and ${ }^{232} T h$ for variety of banana samples.

Several studies have been done about the natural radionuclide concentrations in foodstuff including native fruits throughout the world. But all of the seasonal fruits are not common among the countries. So, it is not possible to compare the studied activity concentrations of ${ }^{238} \mathrm{U},{ }^{232} \mathrm{Th}$ and ${ }^{40} \mathrm{~K}$ in all the seasonal fruits of Bangladesh with the other countries seasonal fruits. But few of the seasonal fruits are in common. The average activity concentrations of ${ }^{238} \mathrm{U},{ }^{232} \mathrm{Th}$ and ${ }^{40} \mathrm{~K}$ for banana in the present study along with the values of other countries are presented in Table 3. The comparison of average activity concentrations of ${ }^{40} \mathrm{~K}$ for banana samples with different countries are graphically displayed in Figure 6. It is observed that the concentration of ${ }^{40} \mathrm{~K}$ for banana in Bangladesh is higher compared with the other countries. Activity concentrations of ${ }^{238} \mathrm{U}$ and ${ }^{40} \mathrm{~K}$ in various fruit samples of different countries with that of the present work 
are presented in Table 4. It is observed that the average activity concentration of ${ }^{40} \mathrm{~K}$ for various fruit samples in Bangladesh is higher compared with the other countries except Thailand as graphically represented in Figure7. Concentrations of naturally occurring radionuclides in fruits of different countries vary widely because of the differing background levels, climate, and agricultural conditions that prevail. Again the uptake of radionuclides by plants from the soil is highly complex and depends on several factors including plant species, soil conditions and the concentration of radionuclides in soil [8].

Table 3. Average activity concentrations of ${ }^{238} U,{ }^{232} \mathrm{Th}$ and ${ }^{40} \mathrm{~K}$ in banana samples for different countrieswith that of the present work.

\begin{tabular}{|c|c|c|c|c|}
\hline \multirow{2}{*}{ Countries } & \multicolumn{3}{|c|}{ Average activity concentrationsinBqkg ${ }^{-1}$} & \multirow{2}{*}{ References } \\
\hline & ${ }^{238} \mathbf{U}$ & ${ }^{232} \mathrm{Th}$ & ${ }^{40} \mathrm{~K}$ & \\
\hline Egypt & - & - & 197.6 & [9] \\
\hline South India & 0.12 & - & 136.62 & {$[10]$} \\
\hline Nigeria & 1.56 & - & 48.77 & [11] \\
\hline Thailand & - & - & 320 & {$[12]$} \\
\hline Indonesia & - & $\overline{1} 8.60$ & 87 & {$[13]$} \\
\hline Bangladesh(Present study) & $\overline{8} .18$ & 3.84 & 354 & \\
\hline
\end{tabular}

Table 4. Activity concentrations of ${ }^{238} U$ and ${ }^{40} \mathrm{~K}$ in fruit samples of different countries with that of the present work.

\begin{tabular}{|c|c|c|c|c|}
\hline \multirow{2}{*}{ Fruits } & \multirow{2}{*}{ Countries } & \multicolumn{2}{|c|}{ Average activity concentrationsin $\mathrm{Bqkg}^{-1}$} & \multirow[b]{2}{*}{ References } \\
\hline & & ${ }^{238} \mathbf{U}$ & ${ }^{40} \mathrm{~K}$ & \\
\hline \multirow{3}{*}{ Mango } & South India & 0.53 & 56.23 & {$[10]$} \\
\hline & Thailand & - & 160 & {$[12]$} \\
\hline & Bangladesh (Present study) & 4.67 & 153.25 & \\
\hline \multirow{2}{*}{ Jackfruit } & Indonesia & - & 85.27 & {$[13]$} \\
\hline & Bangladesh (Present study) & 23.29 & 220.27 & \\
\hline \multirow{3}{*}{ Papaya } & South India & BDL & 59.56 & {$[10]$} \\
\hline & Thailand & - & 840 & {$[12]$} \\
\hline & Bangladesh (Present study) & $\overline{\mathrm{BDL}}$ & 733.25 & \\
\hline \multirow{2}{*}{ Guava } & South India & BDL & 33.40 & {$[10]$} \\
\hline & Bangladesh (Present study) & 24.48 & 347.93 & \\
\hline \multirow{3}{*}{ Pineapple } & Nigeria & 1.86 & 46.45 & {$[11]$} \\
\hline & Thailand & - & 300 & {$[12]$} \\
\hline & Bangladesh (Present study) & BDL & 247.18 & \\
\hline \multirow{2}{*}{ Coconut } & South India & BDL & 58.4 & {$[10]$} \\
\hline & Bangladesh (Present study) & 31.13 & 36.84 & \\
\hline
\end{tabular}

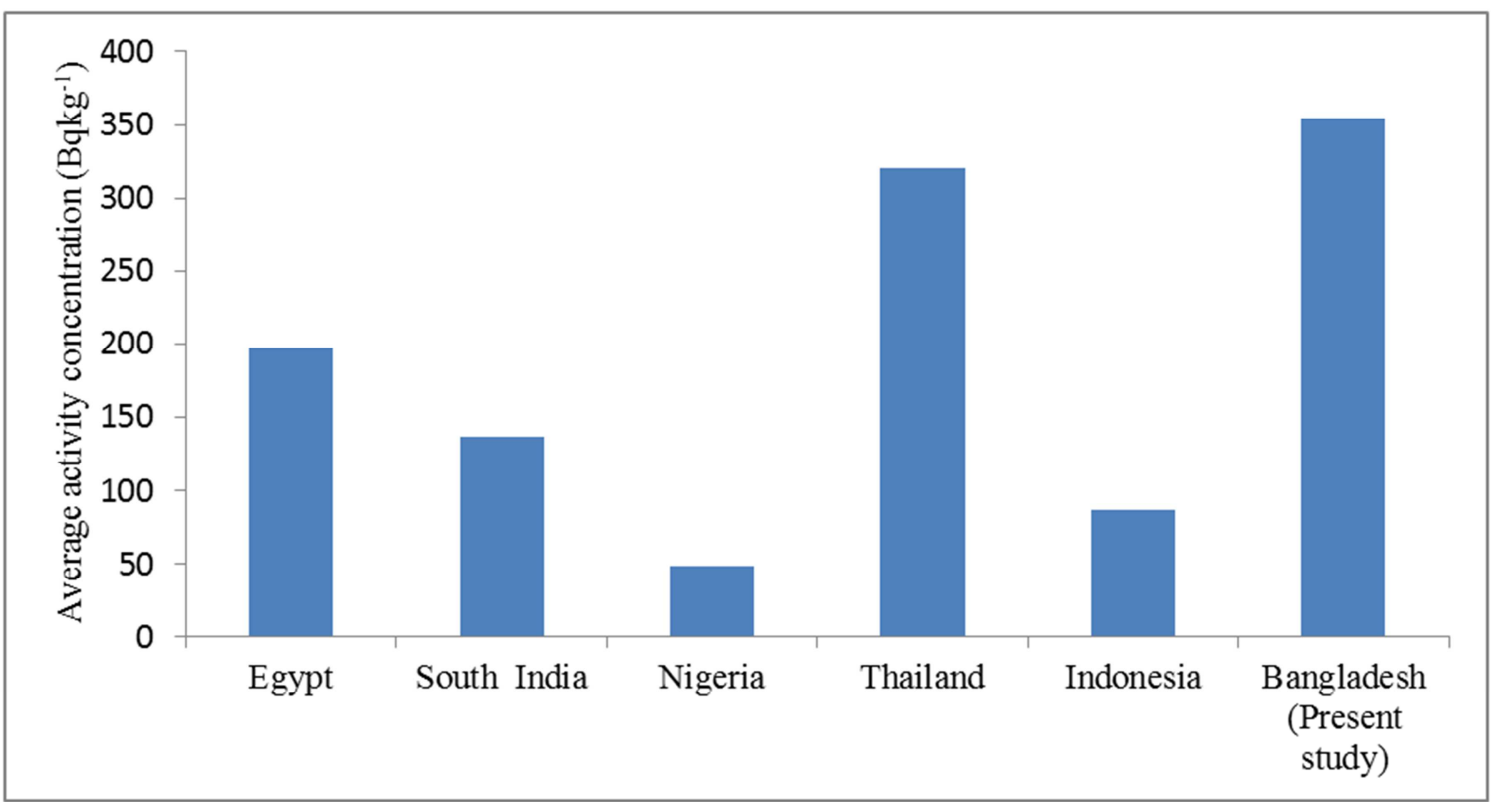

Figure 6. Comparison of average activity concentration of ${ }^{40} \mathrm{Kfor}$ banana samples with different countries. 


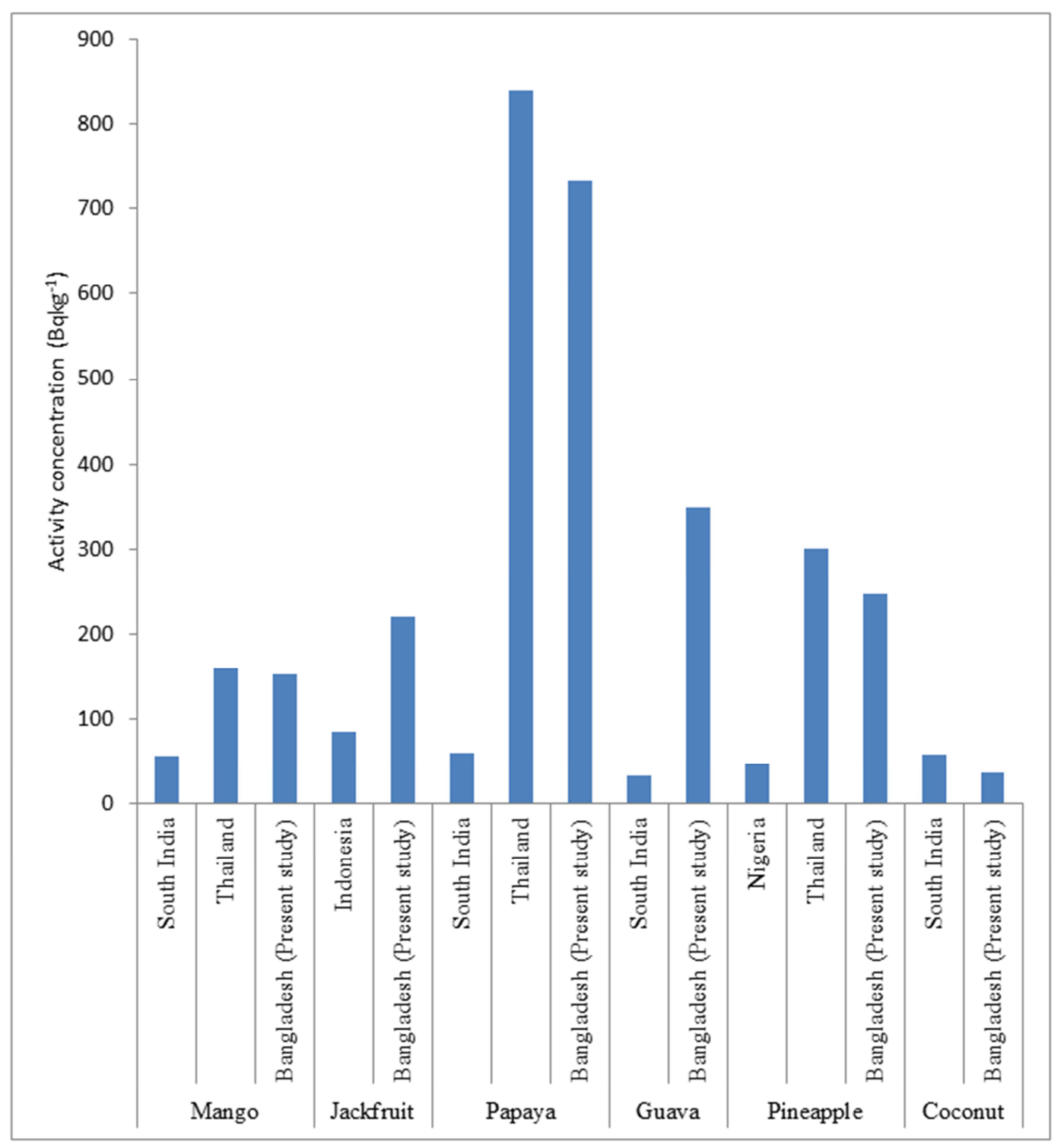

Figure7. Activity concentration of ${ }^{40} \mathrm{~K}$ in various fruit samples of different countries.

The average activity concentrations of ${ }^{238} \mathrm{U},{ }^{232} \mathrm{Th}$ and ${ }^{40} \mathrm{~K}$ are found $10.95,6.68$ and $308.90 \mathrm{Bqkg}^{-1}$ respectively for the collected fruit samples in this present study. A comparison of the world average activity concentration $\left(\mathrm{Bqkg}^{-1}\right)$ of the natural radionuclides in root vegetables and fruits with the results of the present study is given in Table-5. The value of ${ }^{238} \mathrm{U}$ is much lower than the reported value and also the value of ${ }^{232} \mathrm{Th}$ is lower than the reported value by the UNSCEAR for root vegetables and fruits in the whole world [3].

Table 5. Comparison of activity concentration $\left(B q \mathrm{~kg}^{-1}\right)$ of natural radionuclides in fruits.

\begin{tabular}{llll}
\hline Reference & Region & ${ }^{238} \mathbf{U}$ & ${ }^{232} \mathbf{T h}$ \\
\hline UNSCEAR & World average & 318 & 53 \\
Present Study & Bangladesh & 10.95 & 6.68 \\
\hline
\end{tabular}

No peak of man-made fission fragment ${ }^{137} \mathrm{Cs}(661.66 \mathrm{keV})$ was observed in the gamma-ray spectrum. It may be concluded that there are no ${ }^{137} \mathrm{Cs}$ in the fruits of Bangladesh under study. However, it may be stated that the ${ }^{137}$ Cs activity was beyond the detection limit of $1.54 \mathrm{~Bq}$ in our measurement system.

\subsection{Annual Effective Dose Estimation}

The intake of radionuclides with food is dependent on the activity concentration of radionuclides in the various foodstuffs and on the food consumption. It is obvious that food consumption depends on many factors, some of which concern the individual while others are group related. Information on the range and amounts of food consumed regularly by individuals is required. Types of food consumed are related, of course, to the specific geographical, as well as the cultural, economic, social and even political, conditions within and amongst countries [14]. The risk associated with an intake of radionuclides in the body is proportional to the total dose delivered by the radionuclides while staying in the various organs. Intake to effective dose equivalent 
conversion factors is needed in order to convert the intake into dose on ingestion of radionuclides into the body. The intake to dose conversion factors cited in the ICRP publication no. 72 for the members of the public (adults) was used. The factors used for estimate internal effective dosesare: $4.5 \times 10^{-8} \mathrm{~Sv} / \mathrm{Bq}$ for ${ }^{238} \mathrm{U}, 2.3 \times 10^{-7} \mathrm{~Sv} / \mathrm{Bq}$ for ${ }^{232} \mathrm{Th}$ and $6.2 \times 10^{-9} \mathrm{~Sv} / \mathrm{Bq}$ for ${ }^{40} \mathrm{~K}$. From figure 8 , it is shown that Annual Internal doses have been estimated using the average concentrations of ${ }^{238} \mathrm{U},{ }^{232} \mathrm{Th}$ and ${ }^{40} \mathrm{~K}$, ingestion dose coefficients and the fruit consumption rates. The fruit consumption rate in Bangladesh is $44.7 \mathrm{~g}$ /day [14]. The total annual internal effective dose from the consumption of radioactive fruits was found to be $8.39 \mu \mathrm{Sv} / \mathrm{y}$. This indicates that the annual effective dose in fruits samples was lower than the permissible limit of $1 \mathrm{mSv}$ recommended by the International Commission on Radiological Protection [15]. This study was described the dose rate intake of gammaemitting radinuclides for the Bangladeshi consumer. The dose from intake of radionuclides by fruits in general is so low that no harmful effects will occur directly.

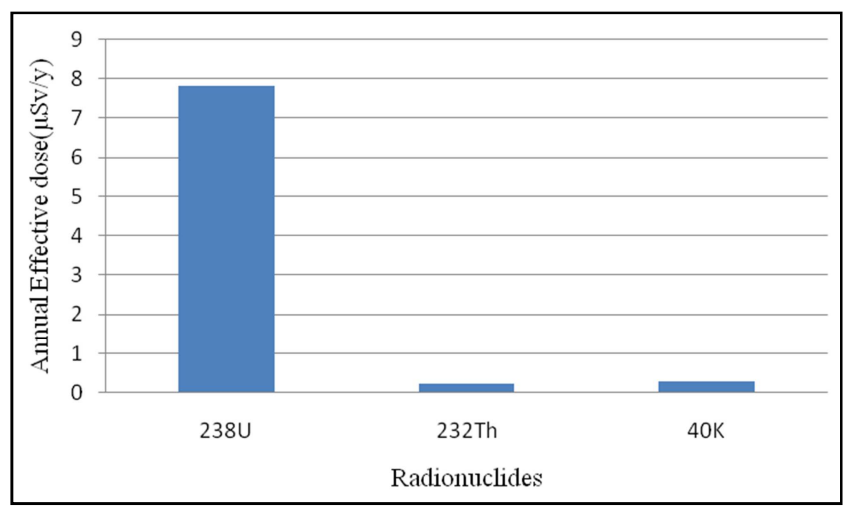

Figure 8. Estimated Annual Effective Dose $(\mu \mathrm{Sv} / \mathrm{y})$ due to intake of Radionuclide from the seasonal Fruits.

\section{Conclusion}

Natural radioactivityand annual effective dose in seasonal fruits sample produced and frequently consumed in Bangladesh were determined in this study. The objective of this research was to investigate the influence of fertilizers and agriculture management on ${ }^{238} \mathrm{U},{ }^{232} \mathrm{Th}$ and ${ }^{40} \mathrm{~K}$ contents in fruits. Activity concentrations of these radionuclides in samples under study were lower than thosereported by UNSCEAR. Also it was found that annual effective doses due to the ingestion of allthree natural radionuclides by adults are below the recommended limit by the International Commission on Radiological Protection for radiological safety.

\section{References}

[1] U. S. Environmental Protection Agency: Radiation Protection Program-Uranium (2015).
[2] A. A. Abojassim, H. N. Hady, Z. B. Mohammed."Natural radioactivity levels in some vegetables and fruits commonly used in Najaf Governorate" Iraq J. Bioen. Food Sci., vol.3 (3) (2016):113-123.

[3] UNSCEAR: Sources and effects of ionizing radiation, Report of the United Nations Scientific Committee on the Effects of Atomic Radiation to the General Assembly, with scientific annexes, United Nations, New York (2000).

[4] F. B. Banzi, Leonard D Kifanga andFelician M Bundala. "Natural radioactivity and radiation exposure at the Minjingu phosphate mine in Tanzania" Journal of Radiological Protection 20(1) (2000):41-51, DOI: 10.1088/0952$4746 / 20 / 1 / 305$.

[5] ICRP: Age-dependent doses to the members of the public from intake of radionuclides -Part 5. Compilation of ingestion and inhalation coefficients. ICRP Publication 72. Ann. ICRP 26(1) (1996).

[6] In. Safety Report Series-99: Derivation of activity concentration values exclusion, exemption and clearance, $\mathrm{pp}$ 1319(2008).

[7] M. F. Hossain, "A Study of Banana Production in Bangladesh: Area, Yield and Major Constraints, ARPN" Journal of Agricultural and Biological Science. Vol. 9(6) (2014): 206210 .

[8] M. Asefi, M. M. Beitollahi, M. Ghiassi-Nejad, and F. RezaNejad, "Exposure to (226)Ra from consumption of vegetables in the high level natural radiation area of Ramsar-Iran" Journal of Environmental Radioactivity Vol.66(3) (2003):215225 .

[9] S. Harb, "Natural Radiospecific activity and Annual Effective Dose in Selected Vegetables and Fruits"Journal of Nuclear and Particle Physics, vol.5(3) (2015): 70-73.

[10] G. Shanthia, , J. Thampi, K. Thanka,., G. Allan GnanaRajc, C. G. Maniyand, "Natural radionuclides in the South Indian foods and their annual dose" Nuclear instruments and Methods in Physics Research Vol.619(1-3) (2010):436-440. DOI 10.1016/j.nima.2009.10.068.

[11] Tchokossal, P., Olomo, J. B., Balogun, F. A. and Adesanmi, C. A. "Assessment of Radioactivity Contents of Food in the Oil and Gas Producing Areas in Delta State, Nigeria" International Journal of Science and TechnologyVol. 3(4) (2013):245-250.

[12] Kranrod, S. Chanyotha, C. Pornnumpa, R. Kritsananuwat, P. Sriploy, "Baseline Data of Naturally Occurring Radionuclides in Some Native Vegetables And Fruits In The Southern Thailand." National Institute of Radiological Sciences, (2014)4:9-1.

[13] Syarbaini, A. Warsona, and D. Iskandar, "Natural Radioactivity in Some Food Crops from Bangka-Belitung Islands, Indonesia” Atom Indonesia Vol. 40(1) (2014): 27-32.

[14] WHO (1988) Derived Intervention Levels for Radionuclide in Food, World Health Organization, Geneva.

[15] ICRP (1996) International Committee of Radiological Protection, Age dependant doses to members of public from intake of radionuclides: compilation of ingestion and inhalation coefficients, ICRP publication 72 (Elsevier Science). 